\title{
Development of Standard Estimates for Garden Construction: Focused on Planting
}

\author{
Kwang-Pyo Hong ${ }^{1}$ and Hyukjae Lee ${ }^{*}$ \\ ${ }^{1}$ Department of Landscape Architecture, Dongguk University, Gyeongju 38066, Korea \\ ${ }^{2}$ The Korean Institute of Garden Design, Seoul 07995, Korea
}

\section{ABSTRACT}

Standard estimates are the numerical data of a unit quantity required for construction work such as the amount of materials, manpower, and the use of equipment required and are also a basis to calculate construction costs. Unfortunately, standard estimates for construction have also been used for garden construction these days as no standard estimates for garden construction have been developed or documented until now. As a result, many problems have arisen at garden construction sites since landscape construction and garden construction differ in terms of scope, size, design and construction methods. The purpose of this study was to develop standard estimates for garden construction for proper calculation of the cost of garden construction and to ensure gardens are created following appropriate construction processes. In order to develop standard estimates for garden construction, a preliminary survey was conducted on experts to understand current issues at first. After that, a questionnaire survey was done to examine problems of construction processes and ways of improvement, and on-site inspections were conducted utilizing CCTVs at construction sites to identify the actual amount of manpower required on site. Based on the results of the surveys and on-site inspections, a draft version of standard estimates for 5 types of planting work for garden construction was developed. Developing standard estimates for garden construction will serve as a stepping stone for the transparent and proper compensation for garden construction work, which will not only contribute to addressing issues between consumers and construction companies, but also to the stabilization of market economy and job creation.

Keywords: CCTV, design charge, onsite inspection, preliminary survey, questionnaire survey

\section{Introduction}

Standard estimates are the quantity of efforts and the quantity of standard materials required to create a unit object using manpower or machinery, and were developed to standardize a unit quantity for construction work based on the types and methods of construction work (Park, 2008). Standard estimates in South Korea were first established in 1962, and since then they have been widely used as a general standard for estimating the cost of construction conducted by the government, local governments and government-invested institutions for about 57 years (Yun and
Lee, 2011a). Since the standard estimates were first established, the government has repeatedly revised and added new standard estimates every year as base data for estimating the cost of public and private construction work in Korea (Lee and Son, 2011). Until now since they were established, however, questions have been continuously raised about whether the results of the existing standard estimates are too high or low as new technologies and construction methods and diversity of construction sites have not been reflected in the existing standard estimates that are based on typical construction methods and construction site conditions (Kim, 2010).

Received: September 19, 2019, Revised: September 25, 2019, Accepted: October 3, 2019

First author: Kwang-Pyo Hong, hkp@dongguk.ac.kr, (D) https://orcid.org/0000-0001-7909-8116

*Corresponding author: Hyukjae Lee, hyuk-jae-lee@hanmail.net, (1) https://orcid.org/0000-0001-6902-2636 
Meanwhile, the history of gardening begins with the history of mankind, and gardens are mostly created by individuals out of necessity. For this reason, there has been no standard cost for creating gardens, and the level of outcomes showed remarkable differences depending on individuals' ability and will.

Meanwhile, changes in the construction industry over time such as the continuous development of construction technology, opening of the construction market and diversified materials have led to the hosting of Suncheon Bay Garden Expo in 2013 (Lee, 2014), the enactment of the Act on the Creation and Furtherance of Arboretums and Gardens by the Korea Forest Service, which resulted in the rapid spread of garden culture. In addition, as the sites of Suncheon Bay Garden Expo 2013 and Taehwagang Garden Show 2018 were designated as a national garden (Kim, 2016), and a number of provincial and municipal gardens were designated, gardens have been transformed from a private space to a public property that has publicness. To create public gardens, it is necessary to maintain the constant quality of construction and also to accurately calculate the cost of construction (Park, 2008).

Landscape construction, similar to garden construction, shows unique characteristics, compared to other types of construction work, such as varied construction conditions depending on natural and geographical conditions (Kang, 2001), and other considerations such as various types of construction work and materials, the small scale and aesthetic quality of construction (Jung, 2012), scattered sites of construction and difficulties in standardizing materials (Park, 2008). For this reason, it has been difficult to reasonably calculate the cost of construction, which resulted in concerns on bad construction and the poor quality of construction (Yun and Lee, 2011b). However, garden construction can be much more unique than landscape construction, and this study was initiated against this backdrop.

In particular, gardens tend to be created on a small scale and focus on aesthetic impression, while parks focus more on practicality (Park, 2018). As such, planting work in creating gardens, unlike the one in doing landscape construction, is expected to show differences in design elements. It seems to be difficult to fully express the intention of garden designers in construction sites with the current standard esti- mates for landscape construction or to properly construct gardens. In particular, considering the characteristics of planting work that requires continuous maintenance, it is necessary to establish independent standards for creating gardens in order to calculate the proper cost of planting. However, standard estimates for landscape construction have been applied until now.

Against this backdrop, this study aimed to develop standard estimates for garden construction in order to address problems that might arise from the cost of construction in garden construction and to improve the quality of garden construction by reflecting the reasonable cost of construction. The development of standard estimates for garden construction is expected to resolve differences between consumers and builders as the foundation stone for paying the proper price, and furthermore to stabilize the market economy and to create jobs.

\section{Research Methods}

\section{Scope of the research}

Gardens have long been created, and can be largely divided into traditional and modern-style gardens. However, since they differ depending on the techniques of creating gardens, materials and shapes, this study focused on modern-style gardens that are newly created. To examine the current status of modern-style gardens, preliminary and questionnaire surveys were conducted, and the types of construction work written on the specifications of landscape construction were utilized. Lastly, on-site inspections were conducted to identify the amount of work required in garden construction, and standard estimates for garden construction were developed for some types of work based on the results.

\section{Preliminary survey}

A preliminary survey was conducted on experts in order to examine the status of garden construction, differences between garden and landscape construction and associated problems. A total of nine experts were surveyed as follows: 
two professors of landscape architecture who served or are serving on the organizing committee of Seoul Garden Show and Taehwagang Garden Show, two landscape architects, three heads of landscaping companies and two garden designers.

The experts who participated in the preliminary survey were informed of the background and purpose of this study on standard estimates for garden construction, and their opinions on the status of garden construction were collected. They freely expressed their opinions, but were encouraged, if possible, to share their negative opinions or objections at the end of the survey.

In the preliminary survey, the following topics were discussed: 1) differences between garden and landscape, 2) differences between garden and landscape construction, and 3) problems that might be caused by these differences. For their better understanding of the topics, photos of show gardens presented in Seoul Garden Show and theme gardens created in apartments, and those of Yeouido Park and Peace Park where Seoul Garden Show was held were shown to the experts.

\section{A questionnaire survey to understand problems from applying landscape construction standard estimates to garden construction}

A questionnaire survey was conducted in order to collect more opinions from those working in the field about the problems and status that were discussed in the preliminary survey. The questionnaire survey was conducted on two groups - landscape architects and garden designers - to identify differences between the two groups.

The questionnaire survey was conducted from September 6 to 10, 2018, and a total of 56 people (29 garden designers, 27 landscape architects) participated in the survey. The general characteristics of the participants were as follows.
The ratio of males and females was 50:50, and the share of those in their $30 \mathrm{~s}$ and $40 \mathrm{~s}$ was $45 \%$ respectively, and those in their $50 \mathrm{~s}, 10 \%$.

The content of the questionnaire survey was listed in Table 1, and the survey was composed of questions on the general characteristics of subjects, and descriptive questions on problems that might arise when applying the existing standard estimates for landscape construction to garden construction, and measures to address the problems. On the problems that might arise from directly applying standard estimates for landscape construction to garden construction, a total of 21 types of work were surveyed using a 5 -point Likert scale $(1=$ not problematic at all; $5=$ extremely problematic).

The 21 types of work were those classified in the specifications of landscape construction, and they can be largely divided into six categories (infrastructure, landscape structures, plantings, landscape facilities, paving and management) and 21 sub-items (Table 2).

The results of the questionnaire survey were analyzed as follows. The reliability of the results was analyzed by calculating Cronbach's alpha, and the utilization rate of standard estimates by type of work was examined. In addition, the t-test was performed on differences in opinion between the two groups.

If all the 21 types of work had been inspected on site, it would have been possible to develop more detailed standard estimates for garden construction. However, it was difficult to conduct on-site inspections on all of them, since the size, shape and design of structures and waterscape facilities varied (Sohn et al., 1990). It is also impossible to examine the status of maintenance by conducting on-site inspections. For this reason, this study conducted on-site inspections on the types of work associated with planting work.

Table 1. Contents of questionnaire

\begin{tabular}{clc}
\hline Category & \multicolumn{1}{c}{ Survey contents } & Method \\
\hline Participants & Years of service, type of work & Nominal scale \\
General statement survey & Problems when applying landscape standard estimates to garden construction & Descriptive \\
& Improvement directions & 5-point Likert scale \\
\hline
\end{tabular}


Table 2. Work classification in landscape construction

\begin{tabular}{ll}
\hline Work classification & \multicolumn{1}{c}{ Sub-level classification } \\
\hline Infrastructures & $\begin{array}{l}\text { Site composition, surface leveling, irrigation } \\
\text { Structures }\end{array}$ \\
Plantings & $\begin{array}{l}\text { Landscape structure, structure, fountains } \\
\text { Trans plantation, tree planting, flower planting, } \\
\text { turf planting }\end{array}$ \\
Facilities & $\begin{array}{l}\text { Outdoor facilities, play facilities, exercise } \\
\text { equipment, lights, landscape stones }\end{array}$ \\
Paving & $\begin{array}{l}\text { Road arrangement, natural paving, artificial } \\
\text { paving }\end{array}$ \\
Management & $\begin{array}{l}\text { Plants management, facilities management, } \\
\text { paving management }\end{array}$ \\
\hline
\end{tabular}

\section{On-site inspection by CCTV}

An on-site inspection was conducted focusing on planting work that was found to have several problems through the questionnaire survey mentioned above. Since the number of facilities and paving work was limited, and their shape varied significantly, they were excluded from this study.

In terms of conducting on-site inspections, Kim (2010) identified the following six problems: absence of detailed methods for on-site inspections; lack of reliability in daily work reports; inaccurate calculation of inspection data on the quantity of work, manpower and working hours; lack of competence of on-site inspectors; difficulties in applying reasonable estimates due to non-compliance of standard specifications; and difficulties in reflecting the characteristics of each site and type of work.

In particular, since garden construction, apart from the problems above, is expected to show more significant differences in design between construction sites, CCTVs were installed on site to record all the process of construction.

A total of 14 sites were selected as follows: 12 show gardens created for the 1st Cheongju Garden Festival (September 15 - October 4, 2018), and the 2nd Cheongju Garden Festival (April 30 - May 29, 2019); and two sites of creating gardens at $\mathrm{P}$ apartment located in Gyeongbuk (November 12 - December 5, 2018). With the cooperation of the sites, one CCTV was installed in each of the show gardens in Cheongju Garden Festival, and three CCTVs were installed in each of the construction sites at $\mathrm{P}$ apartment since the area of the sites was relatively large. Videos were recorded from 6 a.m. to 7 p.m., and a full-HD 2.0 mega-pixel camera and a 6TB recorder were used to cover the sites as far as possible. Videos were recorded throughout the duration of construction.

The recorded videos were analyzed by the researchers of this study, and each detail was checked against the drawings and specifications of the sites and was saved in a database. Any work that was conducted far away from the camera or was blocked was excluded from the data, and the data that can be clearly identified were used. The types of work on which on-site inspections were performed included surface leveling, turf planting, flower planting, shrub planting and tall tree planting.

The recorded videos were classified by site and type of work, and the time required for a skilled (landscaping) worker and a general worker to perform a unit amount of work on a unit area was measured by monitoring the recorded vides, and was saved in a database. Skilled and general workers were identified with the help of construction site managers. The maximum and minimum values and unusual data were excluded from the database. After adjusting the data, the mean, maximum and minimum values were calculated, and compared with the standard estimates for landscape construction.

\section{Developing garden construction standard estimates based on the result of on-site inspection}

Standard estimates for garden construction were developed based on the results of the questionnaire survey and on-site inspections on five types of work associated with planting. The standard estimates for garden construction were developed by using those for landscape construction as a base and adopting an extra charge system depending on the design based on the results of the on-site inspections. Even though the maximum extra charge was applied, it was ensured that the final value did not exceed the mean value of the on-site inspection results in order to avoid an excessive increase in the amount of work (Sohn et al., 1990). The level of extra charges based on the design was determined after comparing the minimum and mean values of the on-site inspection results with the standard estimates for landscape construction (Yun, and Lee, 2011a). 


\section{Results and Discussion}

\section{Preliminary survey}

Differences between landscape and garden construction obtained from the preliminary survey were summarized in Table 3. On the general differences between garden and landscape construction, most of the surveyed experts pointed out that garden construction is mostly ordered by civilians while landscape construction is ordered by government offices or is a part of construction work. They also answered that standard estimates have not been used mandatorily in garden construction ordered by civilians, which was identified as one of the reasons why standard estimates for garden construction have not been developed. However, as more garden construction started to be conducted in public spaces, it seems to be necessary to develop standard estimates for garden construction. In addition, garden construction is mainly performed on a small scale, and is often composed of multiple processes, while the scale of landscape construction is relatively large, and the number of processes is relatively small. The design, execution and maintenance of garden construction are also mainly led by designers, while those of landscape construction are mostly led by separate entities.

In line with differences between garden and landscape construction, differences between planting and facility work were also discussed, and many experts pointed out that landscape construction tends to do planting uniformly using construction equipment, while, in garden construction, trees and plants are planted individually based on the design of gardens, which requires a relatively large amount of work. In addition, when constructing facilities, landscape construction mostly uses ready-made products, but garden construction often makes such products personally, which again requires a larger amount of work. In terms of paving, small-scale gardening projects tend to use various patterns and materials, which was pointed out as a disadvantage for garden construction.

As such, it can be concluded that applying standard estimates for landscape construction to garden construction can cause several problems regarding the cost of construction. However, it was still necessary to further survey them by type of work in detail, and for this reason a questionnaire survey was conducted to understand reasons or causes behind these problems in detail.

\section{The result of questionnaire survey on problems with applying landscape construction standard estimates to garden construction}

The utilization rate of standard estimates for landscape construction by type of work was surveyed as shown in Table 4, and the reliability of the results was examined by calculating Cronbach's alpha. Cronbach's alpha of the group of architects and designers was .831 and .885 respectively, which indicates that the results of the survey were very reliable.

Problems that might arise when applying standard estimates for landscape construction to garden construction were analyzed by group. The designer group was found to view that there were many problems in every type of work except play facilities and exercise equipment which showed a low frequency of use. In particular, structures,

Table 3. Differences between landscape construction and garden construction

\begin{tabular}{cllll}
\hline Category & & Landscape construction & Garden construction & Differences \\
\hline General & Ordered by & Public/Gov't institutions & Civilian, individual & $\begin{array}{l}\text { It is not mandatory to use the standard estimates } \\
\text { in the private construction }\end{array}$ \\
& Scale & Medium to Large & Small to Medium & Garden constructions are relatively small in size \\
& No. of work classification & Relatively low & Relatively high & More work classifications for garden construction \\
& Design & Landscape architecture & Garden designer & \\
& Construction & Landscape constructor & Garden designer & \\
Construction & Planting construction & Construction machine & Garden designer & Design and scale \\
& Facilities construction & Off the shelf & Garden designer & Design and scale \\
\hline
\end{tabular}


waterscape facilities, transplantation, tree planting, flower planting, turf planting and management of plants scored over 4 points, which indicates that when applying standard estimates for landscape construction to garden construction, many problems may arise.

The landscape architect group also scored over 3 points in most types of work, which indicates that they also viewed that utilizing standard estimates for landscape construction in garden construction is problematic. In particular, the score of transplantation, flower planting and management of plants was over 4 , which indicates that many problems might be caused in the types of work.

To identify differences between the two groups, the t-test was conducted. It was found that there was a difference between the two groups in the following types of work: structures, waterscape facilities, tree planting and turf planting. That is, while the garden designer group viewed that there would be many problems in structures, waterscape facilities, tree planting and turf planting, the landscape architect group did not seem to think that way, showing differences in opinion between the two groups.

The reasons why the two groups assessed the types of work as above and measures to address the problems were surveyed using a descriptive question as shown in Table 5 , and the majority of respondents answered that small-scale construction (34 answers), designer work (33 answers), use of equipment (18 answers), and use of various materials (15 answers) require a larger amount of work. In terms of maintenance, 22 respondents answered that designers need to participate in maintenance. Meanwhile, some answered that there would be no problem if extra charges are added to the current standard estimates for landscape

Table 4. Differences in perception of problems with applying landscape construction standard estimate to garden construction by different group

\begin{tabular}{|c|c|c|c|c|c|c|c|}
\hline Work classification & $\begin{array}{l}\text { Garden } \\
\text { designer }\end{array}$ & $\begin{array}{c}\text { Landscape } \\
\text { architect }\end{array}$ & $p$ & Work classification & $\begin{array}{l}\text { Garden } \\
\text { designer }\end{array}$ & $\begin{array}{l}\text { Landscape } \\
\text { architect }\end{array}$ & $p$ \\
\hline Site composition & 3.966 & 3.769 & .365 & Play Facilities & 2.966 & 3.231 & .259 \\
\hline Surface leveling & 3.724 & 3.654 & .827 & Exercise equipment & 2.966 & 3.115 & .547 \\
\hline Irrigation & 3.448 & 3.577 & .498 & Light & 3.138 & 3.577 & .095 \\
\hline Landscape Structure & 4.034 & 3.731 & .120 & Landscape Stone & 3.517 & 3.731 & .440 \\
\hline Structure & 4.276 & 3.731 & $.004 * *$ & Road arrangement & 3.655 & 3.423 & .422 \\
\hline Fountain & 4.345 & 3.731 & $.001 * *$ & Paving (Natural) & 3.793 & 3.846 & .932 \\
\hline Trans plantation & 4.069 & 4.038 & .992 & Paving (Artificial) & 3.862 & 3.462 & .125 \\
\hline Tree planting & 4.379 & 3.692 & $.000 * * *$ & Management (plants) & 4.414 & 4.269 & .596 \\
\hline Flower planting & 4.345 & 4.115 & .113 & Management(facilities) & 3.897 & 3.692 & .511 \\
\hline Turf planting & 4.103 & 3.538 & $.021^{*}$ & Management (paving) & 3.828 & 3.731 & .740 \\
\hline Outdoor facilities & 3.621 & 3.346 & .310 & Cronbach's alpha coefficient & $\alpha=.883(n=29)$ & $\alpha=.835(\mathrm{n}=27)$ & \\
\hline
\end{tabular}

Note. Values indicate mean values on 5-point Likert scale (1: not problematic at all; 5: extremely problematic).

$* p<.05, * * p<.01, * * * p<.001$.

Table 5. Reasons of problems with applying landscape construction standard estimate to garden construction and directions of improvement $(\mathrm{N}=56)$

\begin{tabular}{lclr}
\hline \multicolumn{1}{c}{ Reason } & Frequency & \multicolumn{1}{c}{ Direction of improvement } & Frequency \\
\hline Small scale & 34 & Developing new estimates & 19 \\
Complex design & 33 & Adding labor cost items (garden technician) & 8 \\
Construction machine & 18 & Supplementation of extra charge system & 11 \\
Wide range of materials & 15 & Extra charge in difficulty/design & 10 \\
Cost of creation & 11 & Not necessity & 11 \\
Aesthetic sensibility & 5 & Quote processing & 7 \\
\hline
\end{tabular}


construction (11 answers), and some viewed that even small-scale landscaping projects have similar problems (10 answers).

As a measure to address the problems, some in the garden designer group answered that new standard estimates need to be developed for planting work for gardens (19 answers), and some answered that a new item called garden designer needs to be created under the cost of labor ( 8 answers). However, the landscape architect group suggested the following measures: revising the extra charge system depending on the size (11 answers), adopting an extra charge system depending on the level of difficulty (10 answers), and applying quotations (7 answers).

The results of the questionnaire survey showed that many respondents viewed that applying standard estimates for landscape construction to garden construction can result in lack of work, and that landscape structures, structures, waterscape facilities, transplantation, tree planting, flower planting, turf planting and management of plants can be problematic.

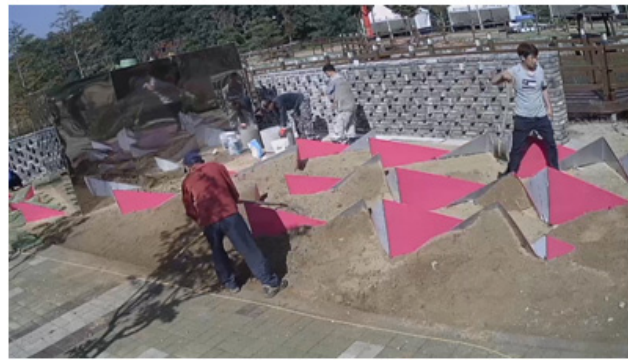

(A)

\section{On-site inspection by CCTV}

In this study, an on-site inspection was conducted on the following types of work among those associated with planting: surface leveling, turf planting, flower planting, shrub planting and tall tree planting.

Surface leveling was performed in a total of 14 sites. Its maximum, minimum and mean values were 0.083 , 0.020 and 0.034 respectively, and all of them were higher than the standard estimate for landscape construction (0.01). The one that showed a high value was (A) site in Fig. 1, and the speed of work in the site was slow due to triangular sculptures. Since plants had to be planted on their slopes, a larger amount of time was required than (B) site, a normal space. The higher value in garden construction than landscape construction can be attributed to the fact that plants needed to be planted within a relatively small area, avoiding impediments like facilities.

Turf planting was performed in a total of 11 sites, and as shown in Fig. 2. (A), when laying turf on designed sculptures, the value obtained from the on-site inspection was

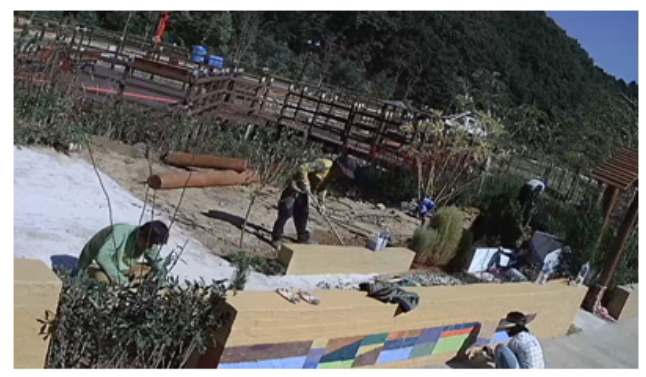

(B)

Fig. 1. Surface leveling in different construction site: (A) work designed by a landscape architect; (B) normal garden construction for an apartment complex.

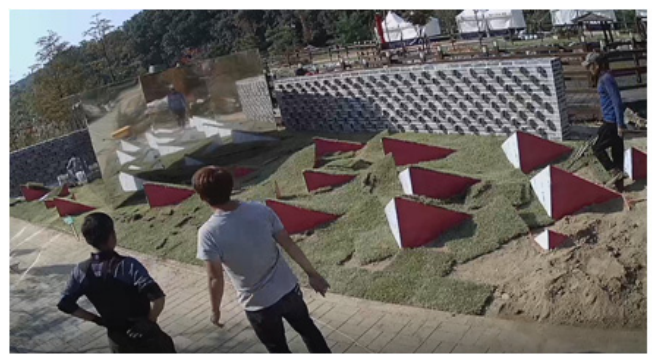

(A)

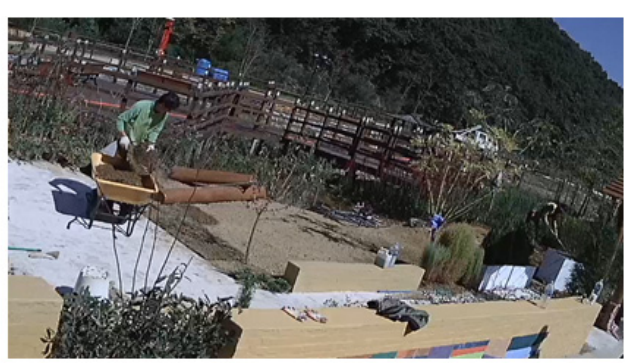

(B)

Fig. 2. Turf planting in different construction site: (A) work designed by a landscape architect; (B) normal garden construction for an apartment complex. 
calculated to be 2.55 , higher than the mean value of the results of the on-site inspection (1.65) and the standard estimate for landscape construction (0.99). As such, turf planting was also found to show differences between sites depending on their design, which proves the necessity of extra charges based on the design of sites.

Flower planting was performed in all the 14 inspected sites. Since it was difficult to identify the process individually on CCTV videos(Fig. 3), the time of work and the quantity of work were calculated based on the provided drawings and specifications. Its minimum, maximum and mean values were $0.33,1.55$ and 0.76 respectively, higher than the standard estimates for landscape construction (0.10, good; 0.15, normal; and 0.24, bad).

However, the value of flower planting differed depending on the site by up to over 10 times, and it was found that the value differed due to differences in design, the location of planting and the type of plants, and that differences in the level of skills and behaviors of workers also caused differences in the time of work. In addition, when garden designers planted flowers by themselves, the speed of work was relatively fast, but hired workers tended to check drawings frequently, which slowed the process.

Shrub planting(Fig. 4) was also performed in all the inspected sites. Since it was difficult to conduct an on-site inspection on every standard, those sized $0.3-0.7 \mathrm{~m}$ (23 sites) were inspected only. Its minimum, maximum and mean values were $0.24,0.36$, and 0.30 respectively, slightly higher than the standard estimate for landscape construction $(0.26)$. In general designs, there was no significant difference from the standard estimates for landscape construction, or the value was slightly lower than the standard estimates. However, the value of those that have distinctive designs tended to be slightly higher.

The standard estimates for tall tree planting were divided into breast height diameter and tree height, but since it was difficult to identify the breast height of tall trees on CCTV videos(Fig. 5), its values were calculated based on the height of trees. In addition, since trees of every size were not planted, tall trees of which height was $1.1-1.5 \mathrm{~m}$ ( 8 sites), and 3.1-3.5m (10 sites) were inspected. The maximum value of $1.1-1.5 \mathrm{~m}$ high trees was 0.18 for landscape technicians, and 0.18 for general workers. In some sites, the value was about 2 times higher than the standard esti-
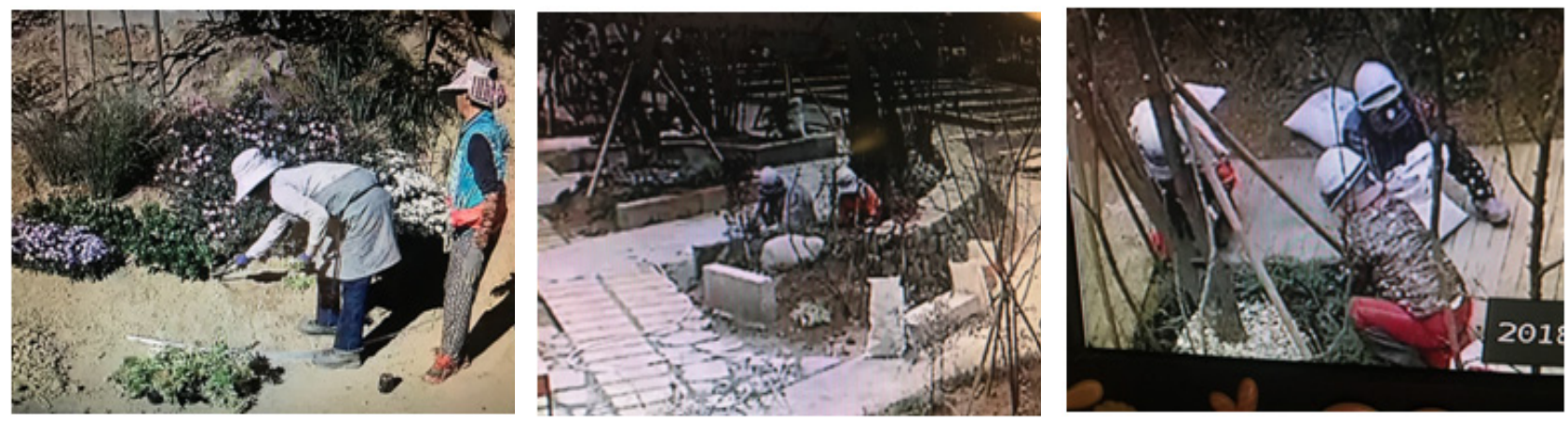

Fig. 3. Flowers planting on construction sites.
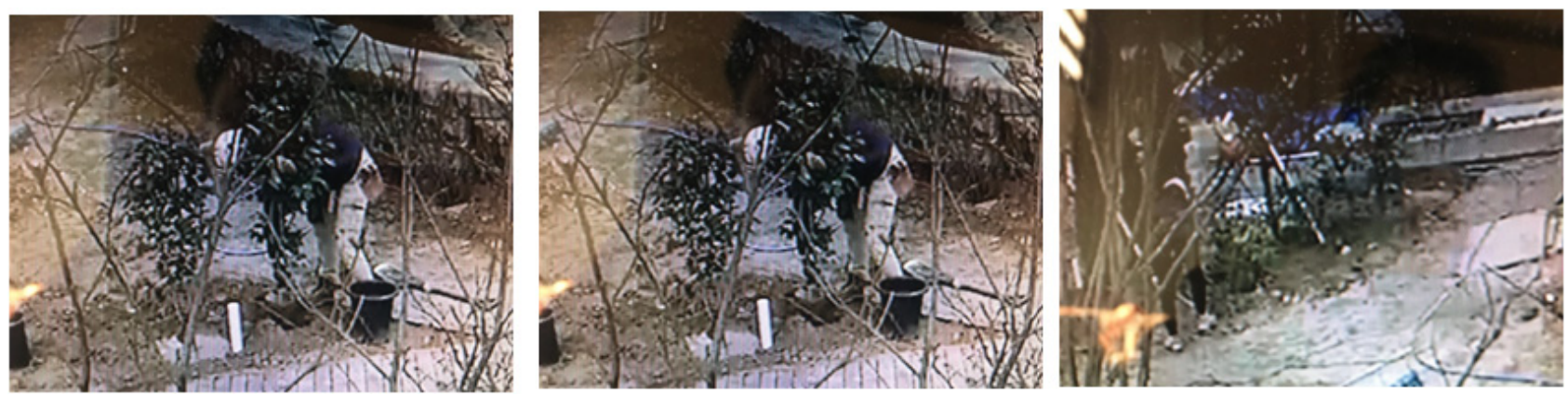

Fig. 4. Shrub planting on construction sites. 
mates for landscape construction, but the value in most sites did not show significant differences from the standard estimates for landscape construction. The sites of which value was lower than the standard estimates for landscape construction used excavators, which shows that although excavators were not used for short trees in the standard estimates for landscape construction, they were often used for short trees on site. The mean value of relatively tall trees of which height was $3.1-3.5 \mathrm{~m}$ was 0.148 for landscape technicians, 0.088 for general workers, and 0.28 for excavators, similar to the standard estimates for landscape construction (0.14, landscape technicians; 0.07 , general workers; and 0.27 , excavators). Still, when a landmark tree was planted, the highest value was obtained (3 sites). Since it had to be planted considering the direction and inclination, more time was required than planting general trees, but those were limited cases. In the case of using excavators, $\mathrm{P}$ apartment of which size was relatively large used an excavator only for one day to plant all the planned tall trees, but Cheongju Gardening Festival used it for 2-3 hours only, which indicates that problems have arisen although they were not identified in the obtained data. These problems are caused by differences in the size of gardening projects, and this has to be addressed going forward.

As such, five different types of work were inspected on site, and the results showed that the standard estimates for landscape construction were not enough to execute garden construction. In particular, depending on the design of gardens, some cases required more work by up to 3-5 times, which indicates that it would be still difficult to apply the standard estimates for landscape construction to garden construction even if the maximum extra charge was applied. Therefore, as garden designers suggested above, it seems to be necessary to develop standard estimates for garden construction.

\section{Development of planting estimates based on the result of on-site inspection}

Standard estimates for garden construction were developed based on the results of the questionnaire survey and on-site inspection on five items associated with planting. Standard estimates for landscape construction were used as a basis, and an extra charge system based on design was applied. It was ensured that the developed estimates would not exceed the mean value of the on-site inspection results, even if the maximum extra charge was applied.

The on-site inspection on surface leveling was conducted, and it was found that when the spaces for garden construction were small and their design was complex, the value of garden construction was up to 8 times higher than the standard estimates for landscape construction. When their design was the simplest, the value of garden construction was nearly equal to the standard estimates for landscape construction. It was found that garden construction required more work about 3-4 times on average than the standard estimates for landscape construction.

The standard estimate for surface leveling for garden construction was developed to be 0.02 for landscape technicians and 0.08 for general workers by using the minimum value out of the results of the on-site inspection (Table 6). In addition, the characteristics of the design of target spaces
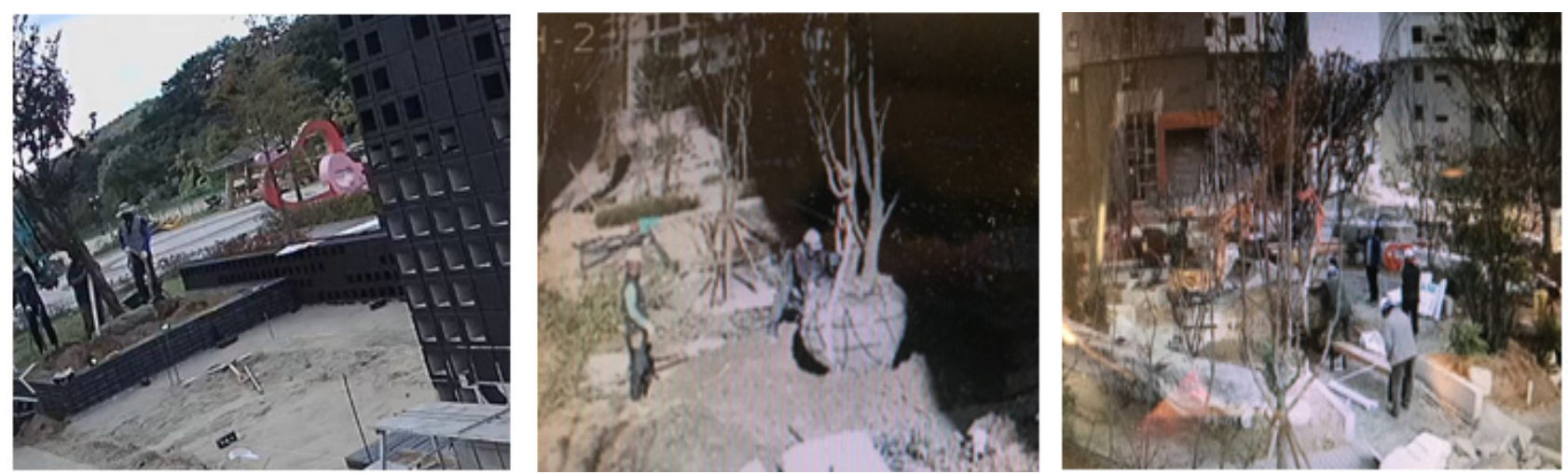

Fig. 5. Tall tree planting on construction sites. 
were divided into simple ( $0 \%)$, normal $(25 \%)$ and complex (50\%) (considering the standard estimates for flower planting for landscape construction). It was allowed to apply an extra charge by up to $50 \%$ in order to ensure that when the design was complex, the value was 0.030 , lower than the mean value of the on-site inspection results (0.034).

Turf planting also showed significant differences from the standard estimates for landscape construction depending on design (working conditions). For this reason, like those for surface leveling, an extra charge system based on design was also applied to turf planting (Table 7). It was allowed to apply an extra charge by up to $30 \%$ based on the results of the on-site inspection. The minimum value out of the results of the on-site inspection was set as the standard estimate for turf planting, and it was ensured that when the maximum extra charge was applied, the value would not exceed the mean value of the results of the on-site inspection. The standard estimate for turf planting for garden construction was set to be 1.25 for landscape workers and 2.31 for general workers.

In the case of flower planting, it was difficult to calculate the value for flower plants individually, and even though CCTVs were installed not to have blind spots, it was difficult to view every corner. For this reason, its values were

Table 6. Development of garden construction standard estimates for surface leveling

\begin{tabular}{|c|c|c|c|}
\hline \multicolumn{2}{|c|}{ Category } & Landscape technician & General worker \\
\hline \multicolumn{4}{|c|}{ Landscape construction standard estimates } \\
\hline Current value & & 0.01 & 0.08 \\
\hline \multirow[t]{3}{*}{ Based on on-site inspection } & Minimum & 0.02 & 0.08 \\
\hline & Mean & 0.03 & 0.08 \\
\hline & Maximum & 0.08 & 0.08 \\
\hline \multicolumn{4}{|c|}{ Garden construction standard estimates ${ }^{\mathrm{z}}$} \\
\hline Simple & & 0.02 & 0.08 \\
\hline Normal & & 0.02 & 0.10 \\
\hline Complex & & 0.03 & 0.12 \\
\hline
\end{tabular}

Note. Standard estimate was calculated per person per $10 \mathrm{~m}^{2}$ surface leveling.

${ }^{\mathrm{z}}$ Simple $=$ Construction is not designed by an architect. Site is wide and flat. Work can be done with speed. Normal $=$ Construction is designed by an architect and there are some work difficulties such as tree planting and landscape stone. Complex $=$ Construction has complex design by an architect and includes risk factors for injury accidents such as slope.

Table 7. Development of garden construction standard estimates for turf planting

\begin{tabular}{|c|c|c|c|}
\hline \multicolumn{2}{|c|}{ Category } & Landscape technician & General worker \\
\hline \multicolumn{4}{|c|}{ Landscape construction standard estimates } \\
\hline Current value & & 0.99 & 2.31 \\
\hline \multirow[t]{3}{*}{ Based on on-site inspection } & Minimum & 1.25 & 2.31 \\
\hline & Mean & 1.65 & 2.55 \\
\hline & Maximum & 2.55 & 2.55 \\
\hline \multicolumn{4}{|c|}{ Garden construction standard estimates ${ }^{z}$} \\
\hline Simple & & 1.25 & 2.31 \\
\hline Normal & & 1.43 & 2.65 \\
\hline Complex & & 1.62 & 3.03 \\
\hline
\end{tabular}

Note. Standard estimate was calculated per person per $100 \mathrm{~m}^{2}$ turf planting.

${ }^{\mathrm{z}}$ Simple $=$ Construction is not designed by an architect. Site is wide and flat. Work can be done with speed. Normal = Construction is designed by an architect and there are some work difficulties such as tree planting and landscape stone. Complex = Construction has complex design by an architect and includes risk factors for injury accidents such as slope. 
calculated based on the drawings and specifications of gardens provided after the construction of the gardens were completed as completion documents by inversely calculating the value based on the total working hours. The values, however, varied depending on the conditions of construction sites, and thus it seems to be necessary to accumulate more data.

The results of the on-site inspection on flower planting showed significant differences from the standard estimates for landscape construction. There were differences in design and the type of plants, but also the level of skills and characteristics of individual workers seemed to significantly affect the differences.

The standard estimates for flower planting for garden construction suggested in this study were as follows (Table 8): when design is simple, 0.33 for landscape technicians and 0.05 for general workers per 100 plants; when design is normal, 0.42 for landscape technicians and 0.06 for general workers per 100 plants; when design is complex, 0.55 for landscape technicians and 0.08 for general workers per 100 plants. The minimum value out of the results of the on-site inspection was set as the standard estimate for simple design, and an extra charge of $30 \%$, slightly lower than the extra charge rate for the standard estimates for landscape construction, was applied to calculate the work re- quired for flower planting when design was normal and complex. In addition, the value when design was complex was ensured not to exceed the mean value of the results of the on-site inspection.

In the case of shrub planting, some sites required a lower amount of work for garden construction than the standard estimates for landscape construction, and some sites required an extra amount of work by about $40 \%$. In most sites, however, the value was similar to the standard estimates for landscape construction. For this reason, in this study, the standard estimates for landscape construction were directly applied to garden construction (Table 9), and it was allowed to apply an extra charge by up to $30 \%$ depending on the level of design. The reason why $20 \%$ was allowed was to maintain the value similar to the mean value of the results of the on-site inspection. In the case of shrub planting, the standard estimates for landscape construction were divided into single and group planting separately, but since group planting was observed in only few sites in this study, data on single planting, except group planting, were collected and used only.

In the case of $1.1-1.5 \mathrm{~m}$ tall tree planting, as the mean value did not show a significant difference from the standard estimates for landscape construction, and the site that showed the minimum value used an excavator, it was diffi-

Table 8. Development of garden construction standard estimates for flower planting

\begin{tabular}{llll}
\hline \multicolumn{1}{c}{ Category } & Landscape technician & General worker \\
\hline $\begin{array}{l}\text { Landscape construction standard estimates } \\
\text { Good working condition }\end{array}$ & & & 0.10 \\
Normal working condition & & 0.15 & 0.05 \\
Poor working condition & Minimum & 0.24 & 0.08 \\
Based on on-site inspection & Mean & 0.33 & 0.13 \\
& Maximum & 0.76 & 0.03 \\
& & 1.55 & 0.15 \\
Garden construction standard estimates & & 0.35 \\
Simple & & & $\mathbf{0 . 3 3}$ \\
Normal & & $\mathbf{0 . 4 2}$ & $\mathbf{0 . 0 5}$ \\
Complex & & $\mathbf{0 . 5 5}$ & $\mathbf{0 . 0 6}$ \\
\hline
\end{tabular}

Note. Standard estimate was calculated per person per 100 flowering plants planting.

${ }^{\mathrm{z}}$ Simple $=$ Construction is not designed by an architect. Site is wide and flat. Work can be done with speed. Normal = Construction is designed by an architect and there are some work difficulties such as tree planting and landscape stone. Complex = Construction has complex design by an architect and includes risk factors for injury accidents such as slope. 
Table 9. Development of garden construction standard estimates for shrub planting

\begin{tabular}{llcc}
\hline \multicolumn{1}{c}{ Category } & & Landscape technician & General worker \\
\hline $\begin{array}{l}\text { Landscape construction standard estimates } \\
\text { Current value }\end{array}$ & & & 0.26 \\
Based on on-site inspection & Minimum & 0.24 & 0.09 \\
& Mean & 0.30 & 0.30 \\
& Maximum & 0.36 & 0.36 \\
Garden construction standard estimates & & & $\mathbf{0 . 2 6}$ \\
$\quad$ Shrub planting & & & $\mathbf{0 . 0 9}$ \\
\hline
\end{tabular}

Note. Standard estimate was calculated per person per 0.3-0.7 $\mathrm{m}$ shrub planting.

${ }^{\mathrm{z}}$ If the design is unique with difficult work conditions of the site, $20 \%$ additional charge is possible.

Table 10. Development of garden construction standard estimates for around $1 \mathrm{~m}$ height tall tree planting

\begin{tabular}{|c|c|c|c|}
\hline \multicolumn{2}{|c|}{ Category } & Landscape technician & General worker \\
\hline \multicolumn{4}{|c|}{ Landscape construction standard estimates } \\
\hline Current value & & 0.09 & 0.07 \\
\hline \multirow[t]{3}{*}{ Based on on-site inspection } & Minimum & 0.06(Excavator) & 0.03 \\
\hline & Mean & 0.09 & 0.08 \\
\hline & Maximum & 0.18 & 0.18 \\
\hline \multicolumn{4}{|c|}{ Garden construction standard estimates } \\
\hline Tall tree planting ${ }^{\mathrm{z}}$ & & 0.098 & 0.086 \\
\hline
\end{tabular}

Note. Standard estimate was calculated per person per tall tree planting (1.1-1.5 m height).

${ }^{\mathrm{z}}$ If design is unique with difficult site conditions for work, $20 \%$ additional charge is possible.

Table 11. Development of garden construction standard estimates for around $3 \mathrm{~m}$ height tall tree planting

\begin{tabular}{|c|c|c|c|c|}
\hline Category & & Landscape technician & General worker & Excavator(hr) \\
\hline \multicolumn{5}{|c|}{ Landscape construction standard estimates } \\
\hline Current value & & 0.14 & 0.07 & 0.27 \\
\hline \multirow[t]{3}{*}{ Based on on-site inspection } & Minimum & 0.06 & 0.06 & 0.30 \\
\hline & Mean & 0.14 & 0.08 & 0.28 \\
\hline & Maximum & 0.22 & 0.11 & 0.30 \\
\hline \multicolumn{5}{|l|}{ Garden construction standard estimates } \\
\hline Tall tree planting ${ }^{\mathrm{z}}$ & & 0.14 & 0.08 & 0.28 \\
\hline
\end{tabular}

Note. Standard estimate was calculated per person per tall tree planting (3.1-3.5 m height).

${ }^{\mathrm{z}}$ If design is unique with difficult site conditions for work, $20 \%$ additional charge is possible.

cult to directly compare them. In addition, the site that showed the maximum value planted a landmark tree, which showed the unique characteristics of garden planting. For this reason, this study suggested to partially apply the maximum value to tall tree planting unlike other types of work, and the mean value, not the minimum value, was applied when developing standard estimates for 1.1-1.5m tall tree planting for garden construction (Table 10). It was allowed to apply an extra charge by up to $30 \%$ (less than the maximum value) depending on the level of design.

The results of $3.1-3.5 \mathrm{~m}$ tall tree planting were similar to those of $1.1-1.5 \mathrm{~m}$ tall tree planting, and thus the mean value was used to develop standard estimates for garden construction (Table 11). In the case of planting landmark trees or those of which design level was high, an extra charge of up to $20 \%$ was allowed to be applied. 


\section{Conclusion}

This study was conducted to calculate the reasonable amount of work required to create gardens in order to address practical problems that may arise when calculating the cost of garden construction. The standard estimates for garden construction were developed by conducting a preliminary survey on experts, a questionnaire survey on landscape architects and garden designers, and on-site inspections in order. The results of these surveys were compared with the existing standard estimates for landscape construction.

Through the preliminary survey conducted on experts, differences between garden and landscape construction, and problems that may be caused by these differences were identified. The results of the questionnaire survey showed that the utilization rate of the standard estimates for landscape construction in garden construction was low in most cases, and there were some differences in opinion between the landscape architect group and the garden design group. Most landscape architects viewed that using the standard estimates for landscape construction in garden construction is problematic in general, and that the standard estimates for landscape construction can be utilized well. However, the majority of garden designers pointed out that new standards estimates need to be developed for garden construction.

After that, on-site inspections were performed in order to examine to what extent such differences between garden and landscape construction were observed on site. To minimize the limits of on-site inspections, CCTVs were utilized to record every construction process. The results of the on-site inspection showed that it is difficult to calculate the work required for garden construction only with the current extra charge system, and that it is necessary to develop standard estimates for garden construction.

Based on the results of the preliminary survey, questionnaire survey and on-site inspections, standard estimates for 5 types of work for garden construction were developed. In the case of surface leveling, its value was about 3 times higher than the standard estimates for landscape construction, and turf planting, about $23-60 \%$, flower planting, about 2.2-3.3 times. However, shrub planting and tall tree planting did not show significant differences from the standard estimates for landscape construction. Gardens that had some design tended to show a higher value than the standard estimates for landscape construction, but other cases did not show significant differences.

As such, differences between garden and landscape construction were found to be caused by the different size and level of design of gardens. These factors can cause differences in the cost of construction, and they were found in actual cases. The development of standard estimates for garden construction is expected to contribute to the development of the garden industry in Korea. In this study, the development of standard estimates for garden construction was focused only on planting, but it is still meaningful to suggest base data for the construction of gardens created in public spaces. It will be necessary to develop standard estimates for other types of work and to conduct studies to increase accuracy.

It is expected to find reasonable answers, to some extent, to problems such as budget shortages for garden construction by utilizing the standard estimates for garden construction developed in this study. However, since on-site inspections were conducted only on 14 sites, it is still necessary to sample more accurately by accumulating more data, and to examine other types of work than planting.

As the necessity of developing standard estimates for garden construction was confirmed in this study, it will be necessary to address problems that might arise due to the lack of time and budget, as identified in this study, by continuously accumulating data through follow-up studies and on-site inspections from a long-term perspective, and to develop accurate standard estimates for garden construction through consultation and consensus between relevant sectors.

\section{References}

Jung, U.S. 2012. A comparative study of cost estimate system for public construction project: In case of landscape architectural construction. Master's thesis, University of Seoul, Seoul, Korea.

Kang, T.H. 2001. Cost estimation of landscape con- 
struction (pp.1-12). Seoul, Korea: Kukje Publishing.

Kim, H.J. 2010. Improvements of survey methods for the efficient enactment and revision for the standard estimation in building construction. Master's thesis, Semyung University, Chungbuk, Korea.

Kim, J.S. 2016. Suncheon bay national garden: Its history and significance. J. Namdo Area Stud. [Suncheon National University] 31:457-474.

Lee, D.E. and C.B. Son. 2011. Identifying the issues relative to enactment and/or revision of construction standard production unit system and its improvement measures. J. Archit. Inst. Korea Struct. Constr. 27(6): $131-140$.

Lee, J.R. 2014. Determinants and processes of regional 9olicy on the International Garden Exposition Suncheon Bay Korea 2013. J. Korean Geogr. Soc. 49(6):849-864.

Park, M.O. 2018. A comparative study on the awareness of concepts for gardens and parks between the experts and general publics. J. Korean Inst. Landsc. Archit. 46(5):1-9.

Park, W.K. 2008. Landscape construction cost estimation. (pp.3-33). Seoul, Korea: Jokyung Publishing.

Sohn, C.K., K.G. Kim, K.Y. Yoon, T.H. Kang, and I.S. Kim. 1990. A study on the amelioration of the standard of estimated unit manpower \& material' in the landscape planting work. J. Korean Inst. Landsc. Archit. 18(3):23-37.

Yun, J.C. and K.H. Lee. 2011a. A studies of amendment a standard of estimated unit manpower and material of landscape architectural construction work classification. J. Korean Inst. Landsc. Archit. 39(5):119-126.

Yun, J.C. and K.H. Lee. 2011b. Comparative studies of standard of estimated unit manpower and material of landscape architecture construction in Korea and Japan. J. Korean Inst. Tradit. Landsc. Archit. 29(3):154-158. 